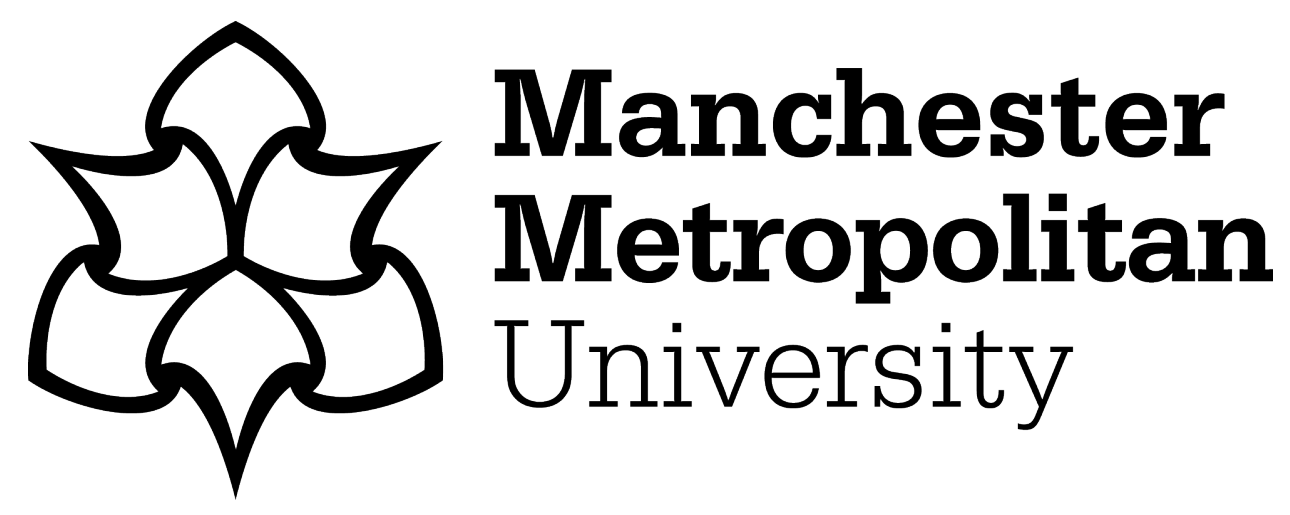

Comfort, P, Dos'Santos, T, Thomas, C, McMahon, JJ and Suchomel, TJ (2018) An investigation into the effects of excluding the catch phase of the power clean on force-time characteristics during isometric and dynamic tasks: An intervention study. Journal of Strength and Conditioning Research, 32 (8). pp. 2116-2129. ISSN 1064-8011

Downloaded from: https://e-space.mmu.ac.uk/626032/

Version: Accepted Version

Publisher: National Strength and Conditioning Association

DOI: https://doi.org/10.1519/JSC.0000000000002656

Please cite the published version 
See discussions, stats, and author profiles for this publication at: https://www.researchgate.net/publication/325679974

\section{An Investigation Into the Effects of Excluding the Catch Phase of the Power Clean on Force-Time Characteristics During Isometric and Dynamic Tasks: An Intervention Study}

Article in The Journal of Strength and Conditioning Research · June 2018

DOI: $10.1519 / \mathrm{JSC} .0000000000002656$

CITATIONS

12

5 authors, including:

Paul Comfort

University of Salford

215 PUBLICATIONS 2,264 CITATIONS

SEE PROFILE

Christopher Thomas

56 PUBLICATIONS 609 CITATIONS

SEE PROFILE
READS

835

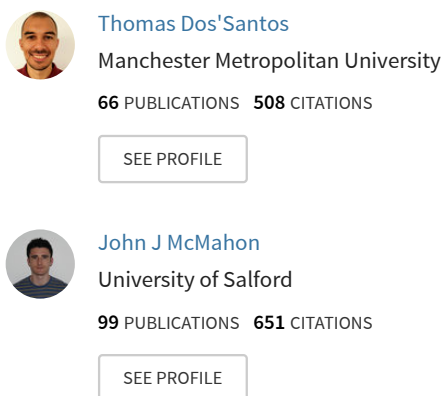

Some of the authors of this publication are also working on these related projects:

The effect of training with a force-velocity overload stimulus using weightlifting derivatives View project

Performance variables in different counter-movement jump strategies between volleyball players with contrasting take-off velocities View project 
1 An investigation into the effects of excluding the catch phase of the power clean on

2 force-time characteristics during isometric and dynamic tasks: an intervention study

3

4 Paul Comfort $^{1 \#}$, Thomas Dos'Santos ${ }^{1}$, Christopher Thomas ${ }^{1,2}$, John. J. McMahon ${ }^{1} \&$ Timothy.

5 J. Suchomel ${ }^{3}$.

6 Author affiliations: ${ }^{1}$ Directorate of Sport, Exercise and Physiotherapy, University of Salford, 7 Frederick Road, Salford, Greater Manchester. UK. ${ }^{2}$ University of South Wales. Pontypridd.

8 Cardiff, Wales. UK. ${ }^{3}$ Department of Human Movement Sciences, Carroll University,

9 Waukesha, WI, USA

10 \# Corresponding author: p.comfort@salford.ac.uk

Running header: Effects of excluding the catch phase of the power clean: an intervention study

15

16

17

18

19

20

21

22

23

24

25

26

27

28 

force-time characteristics during isometric and dynamic tasks: an intervention study

\begin{abstract}
The aims of this study were to compare the effects of the exclusion or inclusion of the catch phase, during power clean (PC) derivatives, on force-time characteristics during isometric and dynamic tasks, after two, four-week mesocycles of resistance training. Two strength matched groups, completed the twice weekly training sessions, either including the catch phase of the $P C$ derivatives (Catch: $n=16$; age $19.3 \pm 2.1$ years; height $1.79 \pm 0.08 \mathrm{~m}$; body mass 71.14 $\pm 11.79 \mathrm{~kg}$; PC one repetition maximum [1-RM] $0.93 \pm 0.15 \mathrm{~kg}^{\mathrm{kg}}{ }^{-1}$ ) or excluding the catch phase (Pull: $n=18$; age $19.8 \pm 2.5$ years; height $1.73 \pm 0.10 \mathrm{~m}$; body mass $66.43 \pm 10.13 \mathrm{~kg}$; PC 1RM $\left.0.91 \pm 0.18 \mathrm{~kg} \mathrm{~kg}^{-1}\right)$. The Catch and Pull groups both demonstrated significant $(p \leq$ 0.007 , power $\geq 0.834$ ) and meaningful improvements in countermovement jump (CMJ) height $(10.8 \pm 12.3 \%, 5.2 \pm 9.2 \%$ ), isometric mid-thigh pull (IMTP) performance (force [F]100: $14.9 \pm$ 17.2\%, $15.5 \pm 16.0 \%$, F150: $16.0 \pm 17.6 \%, 16.2 \pm 18.4 \%$, F200: $15.8 \pm 17.6 \%, 17.9 \pm 18.3 \%$, F250: $10.0 \pm 16.1 \%, 10.9 \pm 14.4 \%$, PF: $13.7 \pm 18.7 \%, 9.7 \pm 16.3 \%)$ and PC 1 RM $(9.5 \pm 6.2 \%$, $8.4 \pm 6.1 \%$ ), pre- to post-intervention, respectively. In contrast to the hypotheses, there were no meaningful or significant differences in percentage change, for any variables, between groups. This study clearly demonstrates that neither the inclusion nor exclusion of the catch phase of the PC derivatives result in any preferential adaptations over two 4-week, in-season strength and power, mesocycles.
\end{abstract}

Key Words: Countermovement Jump; Weightlifting; Performance; Training

\title{
INTRODUCTION
}

Weightlifting exercises (snatch and clean and jerk) and their derivatives are commonly performed in athletes' training programs, with performance in such exercises reported to be related to athletic tasks, such as sprint, agility and jump performances $(29,40)$. These positive associations to performances in athletic tasks may be due to the previously reported similarity in kinetics between weightlifting derivatives (hang snatch) and jump performances (4), with similar observations reported between the second pull phase of the snatch and jump performances by Garhammer and Gregor (18).

Observations of weightlifting performances have established that the second pull phase of the clean and snatch elicits the greatest peak power, compared to the other phases of the lifts (18), albeit using barbell velocity and inverse dynamics to assess peak power applied to it. Furthermore, peak force (PF) and rate of force development (RFD) have also been shown to occur during the second pull phase of the clean and clean pull $(16,39)$. More recently, the 
mid-thigh power clean (PC) and mid-thigh pull have been shown to result in significantly greater ( $p$ <.001) PF, peak RFD (5) and peak power applied to the lifter plus bar system (6) when compared to the hang power clean and PC. Moreover, no significant $(p>0.05)$ differences were observed between these lifts irrespective of the inclusion or exclusion of the catch phase $(5,6)$. In addition, Suchomel et al. (47) reported that the jump shrug, (similar to the mid-thigh pull but initiated with a countermovement and the athlete actually leaves the ground) resulted in significantly $(p<0.05)$ greater PF, peak velocity, and peak power compared to the hang power clean and hang high pull across all loads $(30,45,65,80 \%$ one repetition maximum [1RM] hang clean), indicating that the removal of a catch phase during a PC derivative is not detrimental to the peak power achieved. Similarly, additional studies by Suchomel et al. $(45,46)$ also reported greater relative PF, power, impulse, work, and peak RFD in the jump shrug compared to the hang power clean and hang high pull across loads $(30,45,65,80 \% 1 \mathrm{RM}$ hang clean). More recently, researchers have examined these differences at the joint-level, with Kipp et al. (32) indicating that the jump shrug produces greater magnitudes of joint work and power compared to the hang power clean across several loads.

Recent reviews of weightlifting derivatives also suggested that variations of the $\mathrm{PC}$, which omit the catch phase, namely the clean pull, mid-thigh pull, jump shrug and hang high pull, may be advantageous when training athletes who are less proficient with full weightlifting movements that include the catch phase $(41,43)$. This is supported by additional research that has suggested the use of associate exercises that enhance explosive strength during the second pull movement in less skillful athletes (25). Based on the kinetic similarities of the propulsion phases of the clean derivatives performed with and without the catch phase, it would be feasible to suggest that the elimination of the catch phase should not be detrimental during a training program. In fact, the elimination of the catch phase may provide the opportunity for the athlete to ensure full triple extension of the hips, knees and ankles (plantar flexion), without the possibility of terminating the propulsion phase early to initiate the catch. Ultimately, this may lead to superior training adaptations with regard to PF, RFD, and power during the triple extension movement.

Additionally, the catch phase of the weightlifting derivatives has been suggested to be potentially beneficial in terms of training deceleration and eccentric loading; however, the loading during the catch has been reported to only be comparable to landing during a drop jump (36). More recently, the clean pull from the knee was shown to result in greater mean forces during the load absorption phase compared to the clean and PC from the knee (11). Similarly, Suchomel et al. (44) recently reported greater mean forces during the load absorption phase of the jump shrug compared to the hang high pull and hang power clean. The findings of these studies refute the notion that the catch phase of the clean provides effective eccentric loading. To date, however, there are no published intervention studies that compare the effectiveness of including or excluding the catch during weightlifting derivatives on strength and power characteristics.

The aims of this study, therefore, were to compare the effects of the exclusion or inclusion of the catch phase, during PC derivatives, on force-time characteristics during isometric and dynamic tasks, after two, four-week mesocycles of resistance training. It was hypothesized that both groups would improve across all variables, but that the Pull group (elimination of the catch phase) would result in greater improvements in force-time characteristics assessed during isometric and dynamic performance between groups, compared to the Catch group. 


\section{METHODS}

\section{EXPERIMENTAL APPROACH TO THE PROBLEM}

To determine the effect of the training interventions, on force-time characteristics during isometric and dynamic tasks, a repeated-measures within subject design was utilized, with subjects assessed twice at baseline (48-72 hours apart) to determine reliability, after the initial four week mesocycle, and again after the second four week mesocycle (Figure 1). Furthermore, a between-subjects experimental approach was used to determine differences in changes between intervention groups (Pull vs. Catch). All testing and training occurred inseason, during the middle of the season for each sport. Data was collected across multiple venues, using the same portable equipment, by the same group of researchers.

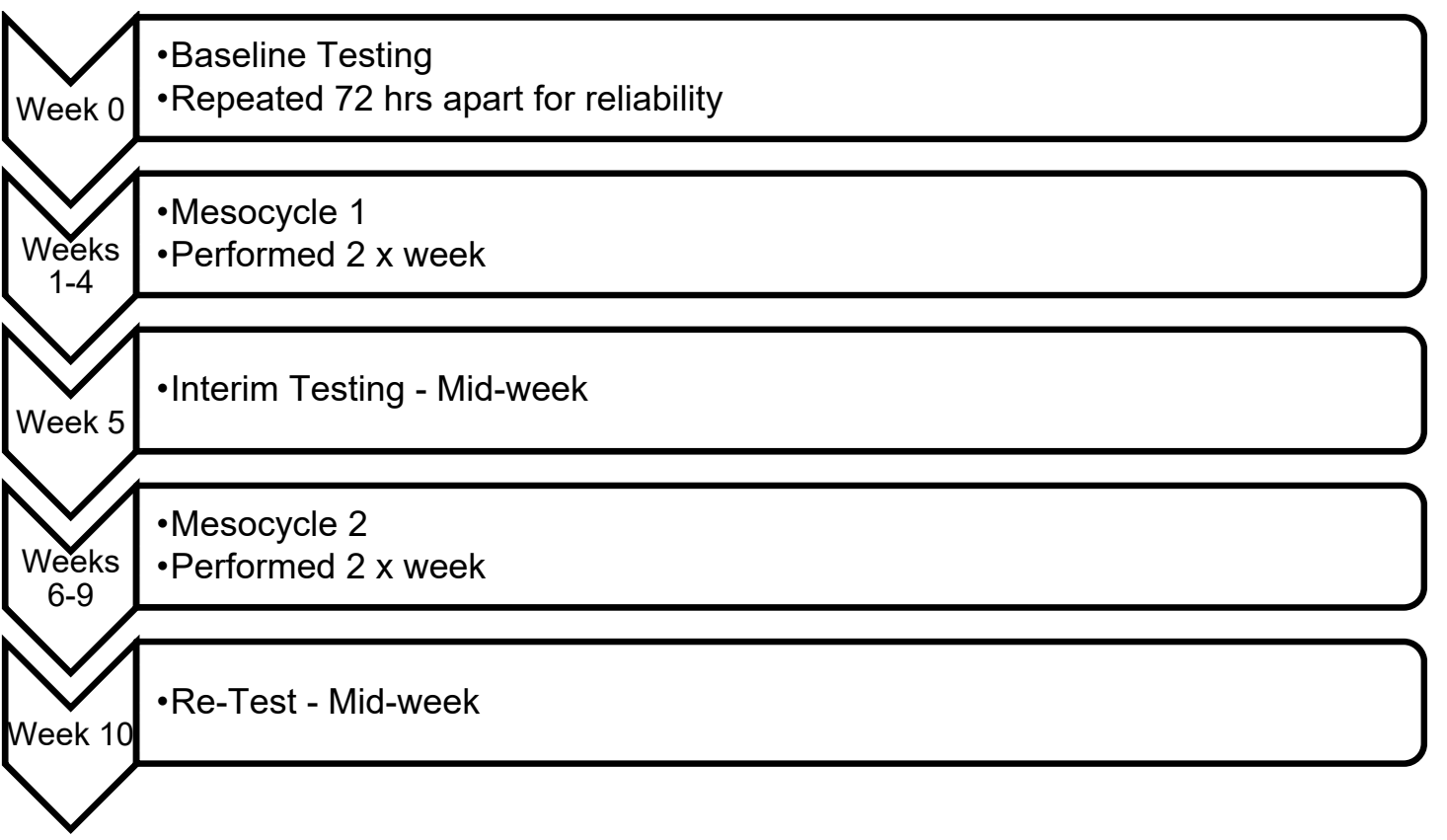

Figure 1: Summary of testing schedule

\section{Subjects}

Professional youth soccer players $(n=18)$ and collegiate athletes $(n=26)$, from the United Kingdom, initially volunteered to participate in this investigation. All subjects were experienced (training age: $3.1 \pm 1.2$ years) and competent in each of the lifts performed in the interventions, as determined by a certified strength and conditioning specialist. After baseline testing subjects were divided into the two groups by matching relative 1RM PC performances, with an equal number of athletes from each sport in both groups. Due to injury from competition and or illness across the duration of the intervention the number of subjects to complete the entire study reduced to 11 professional male soccer players and 23 collegiate athletes who participated in a variety of sports (BMX, rowing, field hockey). Due to drop out, the final mean 1RM PC performance for the groups differed slightly; Catch $(n=16,12$ male, 4 female [5 soccer, 3 BMX, 6 rowing, 2 field hockey]; age $19.3 \pm 2.1$ years; height $1.79 \pm 0.08 \mathrm{~m}$; body mass $71.14 \pm 11.79 \mathrm{~kg}$; 1 RM PC $\left.0.93 \pm 0.15 \mathrm{~kg} \cdot \mathrm{kg}^{-1}\right)$ Pull $(\mathrm{n}=18,14$ male, 4 female [6 soccer, 
$2 \mathrm{BMX}, 7$ rowing, 2 field hockey]; age $19.8 \pm 2.5$ years; height $1.73 \pm 0.10 \mathrm{~m}$; body mass 66.43 $\left.\pm 10.13 \mathrm{~kg} ; 1 \mathrm{RM} P C 0.91 \pm 0.18 \mathrm{~kg} \cdot \mathrm{kg}^{-1}\right)$. A minimum of 11 subjects per groups was required for an a priori power $\geq 0.80$, at an alpha level of $p \leq 0.05$, with post hoc power presented in the results section. This study was approved by the institutional review board, in accordance with the declaration of Helsinki. All subjects provided written informed consent, or parental assent as appropriate.

\section{PROCEDURES}

Prior to testing subjects performed a non-fatiguing standardized warm up consisting of body weight squats, forward and reverse lunges, submaximal squat jumps (SJ) and countermovement jumps (CMJ). Further familiarization and warm up trials were performed prior to the maximal isometric mid-thigh pull (IMTP) and 1RM PC as described below. After the completion of the warm up subjects performed the SJ, CMJ, IMTP and 1RM PC as described below; with testing performed in this sequence to minimize the risk of fatigue or potentiation (Figure 2). All subjects were familiar with all testing procedures as these were included in their 'normal' testing and monitoring procedures. All assessments were conducted by the same experienced researchers.

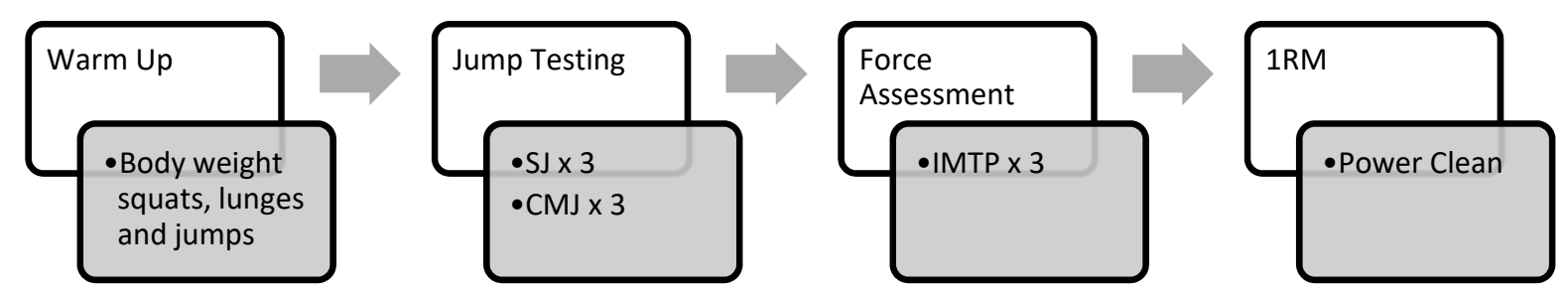

Figure 2: Testing sequence

\section{Jump Performances}

Both SJ and CMJ performances were assessed with subjects standing on a Kistler force platform, sampling at $1000 \mathrm{~Hz}$, with data collected via Bioware 5.11 software (type 9286AA, Kistler Instruments Inc., Amherst, NY, USA). Subjects were instructed to stand still for the initial one second of data collection $(35,38)$ to enable the subsequent determination of body weight (vertical force averaged over one second). Subjects performed three maximal efforts SJ and CMJ, with a one-minute rest between trials and a three-minute rest between the SJ and CMJ. Raw unfiltered, force-time data was exported for subsequent analysis. 
176 For the SJ, subjects placed their hands akimbo, squatted down to a self-selected depth of approximately $90^{\circ}$ knee joint angle, paused for 3 seconds and then jumped as high as possible after a countdown of, ' $3,2,1$, jump'. If there was any obvious countermovement, following visual inspection of the force-time data the jump was excluded, and the subject preformed an additional trial after a one-minute rest.

For the CMJ, subjects were instructed to perform the jumps as fast and as high as possible, whilst keeping their arms akimbo. Any jumps that were inadvertently performed with the inclusion of arm swing or leg tucking during the flight phase were omitted and additional jumps were performed after one minute of rest.

\section{Isometric Mid-thigh Pull Assessment}

For the IMTP, the procedures previously described by Haff et al. $(20,21)$ were used. The minor differences in knee joint angle, which result from differences in ankle dorsiflexion, have been shown to have minimal effect on kinetic variables during the IMTP (7). It was ensured, however, that each subject adopted the posture that they would use for the start of the second pull phase of the clean resulting in knee and hip angles of $133.1 \pm 6.6^{\circ}$ and $145.6 \pm 4.8^{\circ}$ respectively, in line with previous research $(3,21)$. Individual joint angles were recorded and standardized between testing sessions, in line with previous suggestions $(3,15)$. Briefly, for this test, an immovable cold rolled steel bar was positioned at a height, which replicates the start of the second pull phase of the clean, with the bar fixed above the force platform to accommodate different sized participants. Once the bar height was established, the subjects' stood on the force platform with their hands strapped to the bar in accordance with previously established methods (2). Each participant performed two warm-up pulls, one at $50 \%$, and one at $75 \%$ of the participant's perceived maximum effort, separated by one minute of rest.

Once body position was stabilized (verified by watching the participant and force trace), the participants were given a countdown of " $3,2,1$, Pull!". Minimal pre-tension was permitted to ensure there was no slack in the participant's body prior to initiation of the pull, with the instruction to pull against the bar "as fast and hard as possible" (24), and push the feet down into the force plate; this instruction has been previously found to produce optimal testing results (23). Each IMTP trial was performed for approximately five seconds, and all participants were given strong verbal encouragement during each trial. Participants performed three maximal IMTP trials interspersed with two minutes of rest between trials. If PF during all trials did not fall within $250 \mathrm{~N}$ of each other, the trial was discounted and repeated after a further two minutes of rest, in line with previous recommendations $(19,21)$.

Vertical ground reaction force data for the IMTP was collected using a portable force plate sampling at $1000 \mathrm{~Hz}$ (Kistler Instuments, Winterthur, Switzerland), interfaced with a laptop computer and specialist software (Bioware 5.11, Kistler Instruments, Winterthur, Switzerland) that allows for direct measurement of force-time characteristics. Raw unfiltered, force-time data was exported for subsequent analysis.

\section{One Repetition Maximum Power Clean}

The 1RM PC performances were determined based on the standardized NSCA protocol (1). Briefly, subjects performed warm-up PC sets using sub maximal loads prior to performing a maximal attempt, with a progressive increase in loading during the maximal attempts (International Weightlifting Federation, accredited bars and plates were used throughout). Any 
power clean repetition caught with the top of the subject's thighs below parallel was ruled as an unsuccessful attempt.

\section{DATA ANALYSIS:}

\section{Kinetic and Kinematic Variables}

Raw force-time data for both the jumps and the IMTP were analyzed in Microsoft Excel (Excel 2016, Microsoft, Washington, USA). Jump height was calculated from velocity of center of mass at take-off, for both the SJ and CMJ (35). Center of mass velocity was determined by dividing vertical force data (minus body weight) by body mass and then integrating the product using the trapezoid rule. The start of the CMJ was identified in line with current recommendations (38). Take-off was identified when vertical force decreased below five times the standard deviation of the force during the flight phase (residual force) (34).

Reactive strength index modified (RSImod) was calculated using the methods described by previous research (34), where jump height is divided by time to take off ([TTT] combined countermovement, braking and propulsion phase time) during the CMJ.

The maximum forces recorded from the force-time curve during the IMTP trials were reported as the PF and subsequently ratio scaled (PF / body mass). The onset of force production was defined as an increase in force greater than five standard deviations of force during the period of quiet standing (13), and subsequently force at 100-, 150-, 200- and $250 \mathrm{~ms}$ (F100, F150, F200, F250) were also determined and ratio scaled. The average value of the three trials was used for statistical analyses.

\section{INTERVENTION}

Participants were divided into either the Pull group or Catch group and performed the prescribed training on two days per week, under the supervision of certified strength and conditioning specialists. The program consisted of two, 4-week mesocycles (Tables $1 \& 2$ ). The relative training intensity for each group was matched in an attempt to equate the volumeload completed by each group. The loads prescribed for all pulling and catching derivatives were based on the subjects' 1RM PC. The loads prescribed for the remaining exercises were based on predicted 1RM loads based on the subject's previous 5RM performances as determined at the end of their previous phase of training. The volume load during the second session was reduced, as this was the session closest to the subjects' day of competition. All training sessions were supervised by at least one of the authors, who were qualified strength and conditioning coaches (either as a certified strength and conditioning coach with the National Strength and Conditioning Association, an accredited strength and conditioning coach with the United Kingdom Strength and Conditioning Association, or both), to ensure consistency of performance.

The rowers and professional youth soccer players performed between 10-14 hours of skill and conditioning based training per week, in addition to the intervention; while the other subjects performed between 5-8 hours per week of additional training, dependent on their competition schedule, hence initially dividing the subjects equally across groups. 
Table 1: Training sessions, weeks 1-4

\begin{tabular}{|l|l|l|l|l|}
\hline Mesocycle 1: Day 1 & Week 1 & Week 2 & Week 3 & Week 4 \\
\hline Exercise & $3 \times 5 @ 75 \%$ & $3 \times 5 @ 80 \%$ & $3 \times 5 @ 82.5 \%$ & $3 \times 5 @ 67.5 \%$ \\
\hline Back Squat & $3 \times 5 @ 75 \%$ & $3 \times 5 @ 80 \%$ & $3 \times 5 @ 82.5 \%$ & $3 \times 5 @ 67.5 \%$ \\
\hline $\begin{array}{l}\text { Power Clean I } \\
\text { Clean Pulla }\end{array}$ & $3 \times 5 @ 70 \%$ & $3 \times 5 @ 72.5 \%$ & $3 \times 5 @ 75 \%$ & $3 \times 5 @ 60 \%$ \\
\hline Push Press & $2 \times 3$ BW & $3 \times 3$ BW & $3 \times 3$ BW & $3 \times 3$ BW \\
\hline Nordic Lowers & $3 \times 5 @ 65 \%$ & $3 \times 5 @ 70 \%$ & $3 \times 5 @ 55 \%$ \\
\hline $\begin{array}{l}\text { Mesocycle 1: Day 2 } 2 \\
\begin{array}{l}\text { Mid-thigh Power } \\
\text { Clean / Mid-thigh } \\
\text { Pull }\end{array}\end{array} \quad 3 \times 5 @ 60 \%$ & $3 \times 5 \%$ & $3 \times 5 @ 62.5 \%$ \\
\hline RDL & $3 \times 5 @ 70 \%$ & $3 \times 5 @ 75 \%$ \\
\hline $\begin{array}{l}\text { Sets } \times \text { Repetitions @ 1RM \% } \\
\text { BW = Body Weight } \\
\text { aPower clean for the Catch group / Clean pull for the Pull group } \\
\text { bMid-thigh power clean for the Catch group / Mid-thigh pull for the Pull group }\end{array}$ \\
\hline
\end{tabular}

Table 2: Training sessions, weeks 6-9

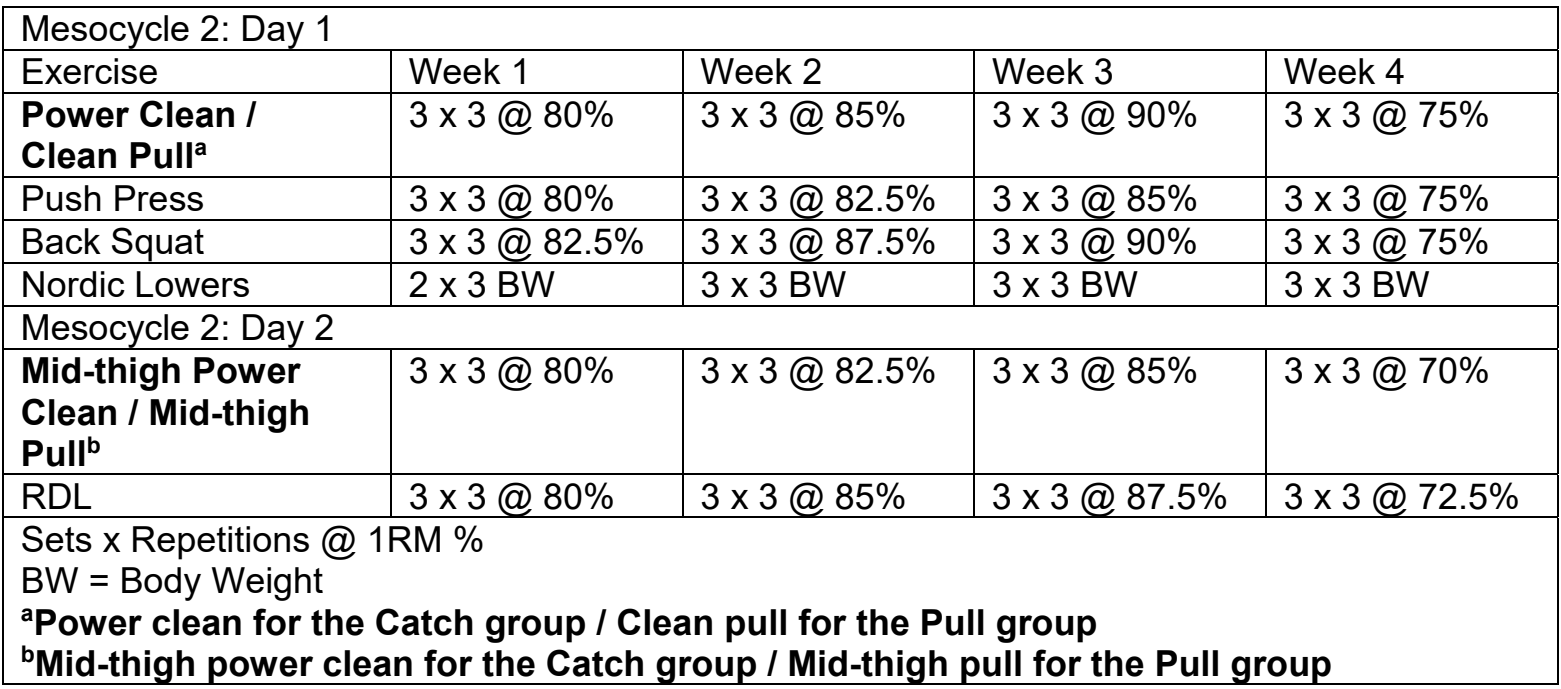

\section{Statistical Analyses}

Normality of all data was determined via Shapiro-Wilk's test of normality, with all variables being normally distributed. Baseline measures were compared to determine within- and between-session reliability, as appropriate, using two-way random effects model intraclass correlation coefficients (ICC) and 95\% confidence intervals. To assess the magnitude of the $I C C$, the values were interpreted as low $(<0.30)$, moderate $(0.30-0.49)$, high $(0.50-0.69)$, very high (0.70-0.89), nearly perfect (0.90-0.99), and perfect (1.0) (28). Percentage coefficient of variation $(\% \mathrm{CV})$ was also calculated to determine the within session variability, with $<10 \%$ classified as acceptable (12). In addition, t-tests were performed and Cohen's $d$ effect sizes calculated to determine if there were any significant or meaningful differences between the baseline testing sessions. 


6

7

A series of two-way repeated-measures analyses of variance $(3 \times 2$; time $\times$ group), with Bonferroni post-hoc analysis, were performed to determine changes in the aforementioned kinetic and kinematic variables at each time point. A series of $\mathrm{t}$-tests were performed to determine differences in the percentage change between phases (pre-mid, mid-post, pre-post) and between groups (Catch vs. Pull), for each variable. An a priori alpha level was set at $p$ $\leq 0.05$. Further, the magnitude of any changes were determined via the calculation of effect sizes (Cohen's $d$ ), classified as trivial $(\leq 0.19)$, small $(0.20-0.59)$, moderate $(0.60-1.19)$, large $(1.20-1.99)$, and very large $(2.0-4.0)(27)$. All statistical analyses were performed using SPSS (Version 23. IBM, New York, NY).

\section{Results}

Between session 1RM PC performances were highly reliable $(\mathrm{ICC}=0.997,0.998)$ with a very low variability $(\mathrm{CV}=0.23 \%, 0.13 \%)$ between sessions one $(67.58 \pm 23.06 \mathrm{~kg} ; 0.94 \pm 0.19$ kg. kg $\left.{ }^{-1}\right)$ and two $\left(67.36 \pm 22.59 \mathrm{~kg} ; 0.93 \pm 0.19 \mathrm{~kg}^{\mathrm{kg}}{ }^{-1}\right)$, for both absolute and relative performances, respectively.

Reliability of all jump variables demonstrated was very high to nearly perfect both within (ICC $=0.819-0.976)$ and between $(I C C=0.870-0.981)$ sessions, with low variability (CV $=0.27-$ $5.96 \%)$ between trials. Furthermore, differences between sessions were trivial to small $(d=$ 0.03-0.22) and not significant (Table 3).

Reliability of all IMTP variables demonstrated was very high to nearly perfect both within (ICC $=0.879-0.983)$ and nearly perfect $(I C C=0.966-0.981)$ between sessions, with acceptable variability $(\mathrm{CV}=5.36-12.78 \%)$ between trials, with the variability reducing progressively with the time-point at which force was assessed. Furthermore, differences between sessions were trivial $(d=0.03-0.22)$ and non-significant $(p>0.05)$ (Table 4$)$.

8


317 Table 3: Within and between session reliability (ICC (95\% confidence intervals)) and variability 318 (\% coefficient of variation) of jump performance variables

\begin{tabular}{|c|c|c|c|}
\hline Variable & & Session 1 & Session 2 \\
\hline \multirow{7}{*}{ SJ Height (m) } & Mean & 0.281 & 0.266 \\
\hline & SD & 0.069 & 0.068 \\
\hline & Within & 0.944 & 0.962 \\
\hline & Session ICC & $(0.881-0.977)$ & $(0.920-0.984)$ \\
\hline & $\begin{array}{c}\text { Between } \\
\text { Session ICC }\end{array}$ & \multicolumn{2}{|c|}{$\begin{array}{c}0.870 \\
(0.661-0.951)\end{array}$} \\
\hline & $\% \mathrm{CV}$ & 5.06 & 0.27 \\
\hline & $d$ & \multicolumn{2}{|c|}{0.22} \\
\hline \multirow{7}{*}{$\begin{array}{l}\text { CMJ Height } \\
\text { (m) }\end{array}$} & Mean & 0.316 & 0.318 \\
\hline & SD & 0.072 & 0.071 \\
\hline & Within & 0.954 & 0.981 \\
\hline & Session ICC & $(0.903-0.981)$ & $(0.959-0.992)$ \\
\hline & $\begin{array}{c}\text { Between } \\
\text { Session ICC }\end{array}$ & \multicolumn{2}{|c|}{$\begin{array}{c}0.971 \\
(0.925-0.989)\end{array}$} \\
\hline & \%CV & 4.15 & 2.78 \\
\hline & $d$ & \multicolumn{2}{|c|}{0.03} \\
\hline \multirow{7}{*}{ CMJ TTT (s) } & Mean & 0.73 & 0.72 \\
\hline & SD & 0.08 & 0.10 \\
\hline & Within & 0.819 & 0.854 \\
\hline & Session ICC & $(0.652-0.921)$ & $(0.710-0.937)$ \\
\hline & $\begin{array}{c}\text { Between } \\
\text { Session ICC }\end{array}$ & \multicolumn{2}{|c|}{$\begin{array}{c}0.893 \\
(0.719-0.960)\end{array}$} \\
\hline & \%CV & 3.06 & 2.86 \\
\hline & $d$ & \multicolumn{2}{|c|}{0.13} \\
\hline \multirow{6}{*}{ CMJ RSImod } & Mean & 0.44 & 0.45 \\
\hline & SD & 0.10 & 0.11 \\
\hline & $\begin{array}{l}\text { Within } \\
\text { Session ICC }\end{array}$ & $\begin{array}{c}0.906 \\
(0.809-0.960)\end{array}$ & $\begin{array}{c}0.940 \\
(0.875-0.975)\end{array}$ \\
\hline & $\begin{array}{l}\text { Between } \\
\text { Session ICC }\end{array}$ & \multicolumn{2}{|c|}{$\begin{array}{c}0.976 \\
(0.933-0.991)\end{array}$} \\
\hline & \%CV & 5.96 & 5.04 \\
\hline & $d$ & \multicolumn{2}{|c|}{0.12} \\
\hline
\end{tabular}

SJ: squat jump, CMJ: countermovement jump, TTT: time to takeoff, RSImod: reactive strength index modified, SD: standard deviation, ICC: intraclass correlation coefficient, \%CV: percentage coefficient of variation, $d$ : Cohen's $d$ effect size 
324 Table 4: Within and between session reliability (ICC (95\% confidence intervals)) and variability 325 (\% coefficient of variation) of IMTP variables

\begin{tabular}{|c|c|c|c|}
\hline Variable & & Session 1 & Session 2 \\
\hline \multirow{6}{*}{ F100 ms (N.kg $\left.{ }^{-1}\right)$} & Mean & 20.32 & 20.35 \\
\hline & SD & 6.23 & 5.20 \\
\hline & $\begin{array}{c}\text { Within } \\
\text { Session ICC }\end{array}$ & $\begin{array}{c}0.937 \\
(0.869-0.974)\end{array}$ & $\begin{array}{c}0.908 \\
(0.798-0.963)\end{array}$ \\
\hline & $\begin{array}{c}\text { Between } \\
\text { Session ICC }\end{array}$ & $\begin{array}{r}0 \\
(0.945\end{array}$ & $\begin{array}{l}30 \\
.992)\end{array}$ \\
\hline & \%CV & 5.50 & 12.78 \\
\hline & $d$ & \multicolumn{2}{|c|}{0.01} \\
\hline \multirow{7}{*}{ F150 ms (N.kg-1) } & Mean & 25.18 & 25.01 \\
\hline & SD & 7.92 & 6.15 \\
\hline & Within & 0.925 & 0.903 \\
\hline & Session ICC & $(0.845-0.969)$ & $(0.786-0.961)$ \\
\hline & $\begin{array}{c}\text { Between } \\
\text { Session ICC }\end{array}$ & $\begin{array}{r}0 \\
(0.90\end{array}$ & $\begin{array}{l}6 \\
.987)\end{array}$ \\
\hline & \%CV & 6.28 & 11.62 \\
\hline & $d$ & \multicolumn{2}{|c|}{0.02} \\
\hline \multirow{6}{*}{ F200 ms (N.kg $\left.{ }^{-1}\right)$} & Mean & 28.73 & 28.28 \\
\hline & SD & 8.72 & 6.76 \\
\hline & $\begin{array}{c}\text { Within } \\
\text { Session ICC }\end{array}$ & $\begin{array}{c}0.935 \\
(0.865-0.973)\end{array}$ & $\begin{array}{c}0.812 \\
(0.64-0.918)\end{array}$ \\
\hline & $\begin{array}{l}\text { Between } \\
\text { Session ICC }\end{array}$ & $\begin{array}{r}0.913 \\
(0.96\end{array}$ & $\begin{array}{l}7.04-0 .(10) \\
.988)\end{array}$ \\
\hline & \%CV & 5.82 & 8.94 \\
\hline & $d$ & \multicolumn{2}{|c|}{0.05} \\
\hline \multirow{6}{*}{ F250 ms (N.kg-1) } & Mean & 30.32 & 30.06 \\
\hline & SD & 9.05 & 7.40 \\
\hline & Within & 0.953 & $\begin{array}{c}0.879 \\
(076199)\end{array}$ \\
\hline & $\begin{array}{l}\text { Session ICC } \\
\text { Between } \\
\text { Session ICC }\end{array}$ & $\begin{array}{r}(0.902-0.981) \\
0.94\end{array}$ & $\begin{array}{l}(0.761-0.949) \\
8 \\
992)\end{array}$ \\
\hline & $\begin{array}{c}\text { \%CV } \\
\text { Cession ILC }\end{array}$ & 5.36 & 6.19 \\
\hline & $d$ & \multicolumn{2}{|c|}{0.03} \\
\hline \multirow{7}{*}{ Peak Force (N.kg-1) } & Mean & 38.19 & 38.91 \\
\hline & SD & 12.24 & 11.70 \\
\hline & Within & 0.983 & 0.968 \\
\hline & Session ICC & $(0.964-0.993)$ & $(0.930-0.987)$ \\
\hline & $\begin{array}{c}\text { Between } \\
\text { Session ICC }\end{array}$ & $\begin{array}{r}0 \\
(0.95\end{array}$ & $\begin{array}{l}31 \\
.993)\end{array}$ \\
\hline & \%CV & 3.44 & 4.29 \\
\hline & $d$ & \multicolumn{2}{|c|}{0.06} \\
\hline
\end{tabular}

SD: standard deviation, ICC: intraclass correlation coefficient, \%CV: percentage coefficient of variation, $d$ : Cohen's $d$ effect size 


\section{JUMP PERFORMANCES}

Sphericity was assumed via Mauchley's test for all jump variables. The Catch group achieved significant $(p<0.001$; power $=0.794)$ improvements in SJ height across the duration of the intervention, with moderate and significant increase $(12.6 \pm 10.2 \%, p<0.001)$ from pre- to post-intervention. In contrast, post-hoc analysis demonstrated that changes were small and non-significant $(p>0.05)$ between pre- and mid-intervention and mid- and post-intervention. There was only a trivial and non-significant increase $(2.1 \pm 11.8 \%, p>0.05)$ in SJ performance for the Pull group (Table 5). The Catch group exhibited greater improvements in SJ height preto mid-intervention $(8.8 \pm 13.1 \%)$, mid- to post-intervention $(4.1 \pm 7.9 \%)$, or pre- to postintervention (12.6 $\pm 10.2 \%)$, compared to the Pull group $(2.1 \pm 11.8 \%, 1.9 \pm 12.8 \%, 4.0 \pm$ $17.6 \%$, respectively), although these were small and not significantly different $(d=0.20-0.59$; $p>0.05$ ) (Figure 3a).

The Catch group and Pull groups both achieved significant $(p<0.001$; power $=0.980 ; p=0.04$; power $=0.810$, respectively) improvements in CMJ height across the duration of the intervention. The results of post-hoc analysis demonstrated that changes were small and nonsignificant $(p>0.05)$ between pre- and mid-intervention and mid- to post-intervention for the Catch group, with a small yet significant $(10.8 \pm 12.3 \%, p=0.007)$ increase from pre- to postintervention. The Pull group achieved trivial and non-significant increases between pre- and mid-intervention and mid- to post-intervention, with small but significant increases $(5.2 \pm 9.2 \%$, $p=0.04$ ) pre- to post-intervention (Table 5). The Catch group exhibited greater improvements in CMJ height pre- to mid-intervention (5.4 $\pm 9.6 \%)$, mid- to post-intervention (5.1 $\pm 6.5 \%)$, or pre-to post-intervention (10.8 $\pm 12.3 \%)$, compared to the Pull group $(3.7 \pm 8.0 \%, 1.6 \pm 7.2 \%$, $5.2 \pm 9.2 \%$, respectively), although these were trivial to small and non-significant $(d=0.19$ $0.52 ; p>0.05$ ) (Figure 3b). 

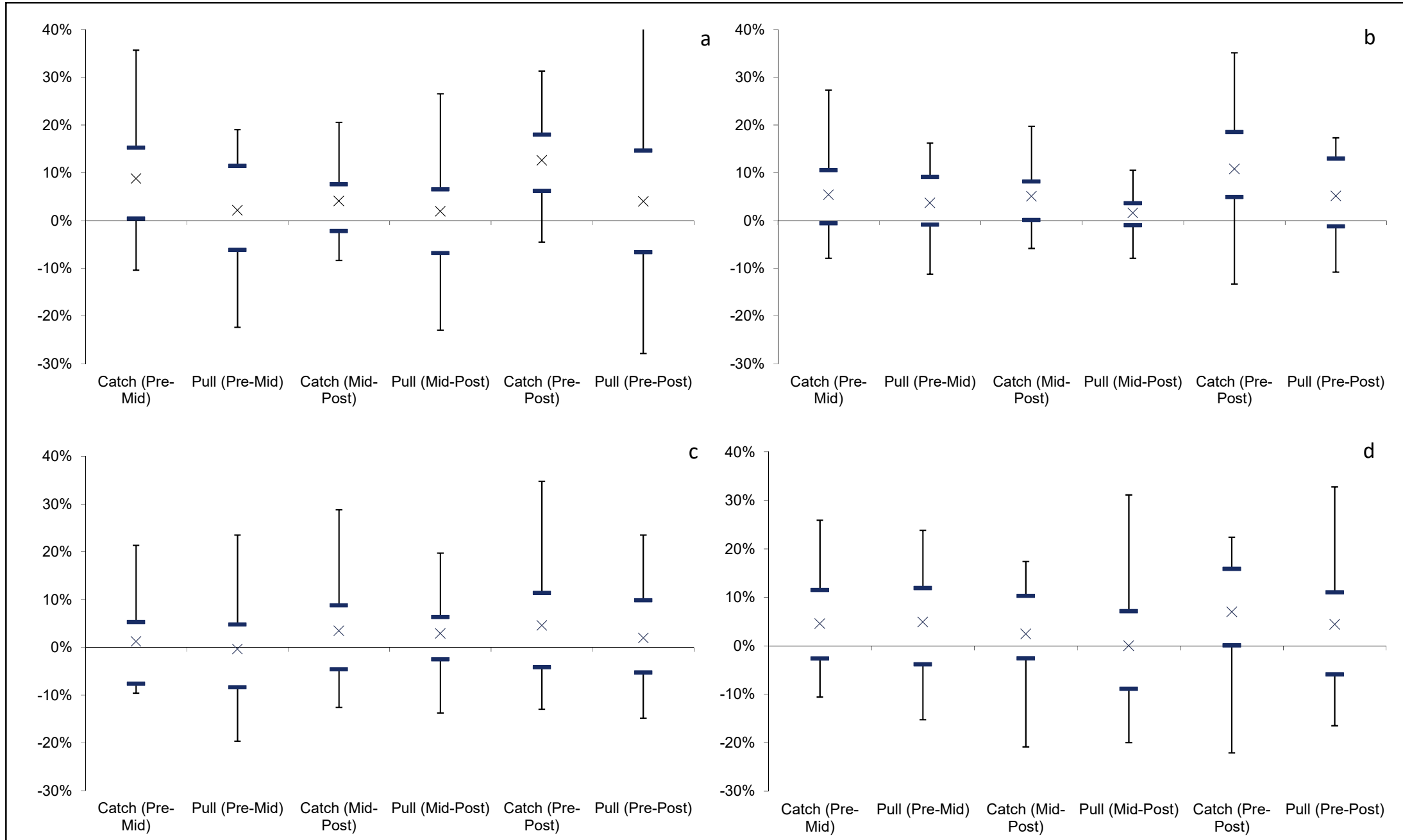

Figure 3: Comparison of percentage change in jump variables, across time points, for the Catch and Pull groups (SJ = squat jump; $\mathrm{CMJ}=$ countermovement jump; RSImod = reactive strength index modified) 
For CMJ TTT there were trivial to small non-significant differences for both the Catch and Pull groups across all time points. There were trivial to small and non-significant differences ( $p$ $>0.05)$ in percentage change TTT pre- to mid-intervention $(1.2 \pm 8.8 \%,-0.4 \pm 12.2 \%, d=0.15)$, mid- to post-intervention $(3.5 \pm 11.0 \%, 2.9 \pm 10.6 \%, d=0.06)$, and pre-post $(4.6 \pm 13.5 \%, 2.0$ $\pm 12.0 \%, d=0.20$ ), between the Catch and Pull groups, respectively (Table 5, Figure $3 \mathrm{c}$ ). There were only trivial to small changes in RSImod for both groups across all time points (Table 5), with trivial to small and non-significant differences $(p>0.05)$ in percentage change in RSImod across phases (pre-mid: $4.6 \pm 10.0 \%, 4.9 \pm 10.1 \%, d=0.03$, mid-post: $2.4 \pm 10.4 \%$, $0.0 \pm 13.7 \%, d=0.20$, pre-post: $7.0 \pm 13.4 \%, 4.4 \pm 14.1 \%, d=0.19$ ), between the Catch and Pull groups, respectively (Figure $3 \mathrm{~d}$ ).

Table 5: Changes in jump performance

\begin{tabular}{|c|c|c|c|c|c|c|c|}
\hline \multirow{2}{*}{ Variable } & \multirow[t]{2}{*}{ Group } & \multicolumn{3}{|c|}{ Catch } & \multicolumn{3}{|c|}{ Pull } \\
\hline & & Pre & Mid & Post & Pre & Mid & Post \\
\hline \multirow{6}{*}{ SJ Height (m) } & Mean & 0.283 & 0.305 & 0.317 & 0.283 & 0.287 & 0.289 \\
\hline & SD & 0.052 & 0.048 & 0.053 & 0.061 & 0.057 & 0.055 \\
\hline & $\% \mathrm{CV}$ & 4.40 & 4.95 & 2.74 & 5.64 & 4.06 & 3.36 \\
\hline & & \multicolumn{3}{|c|}{0.44} & \multicolumn{2}{|c|}{0.05} & \\
\hline & $d$ & \multirow{2}{*}{\multicolumn{3}{|c|}{$0.64^{*}{ }^{0.24}$}} & \multicolumn{3}{|c|}{0.05} \\
\hline & & & & & & 0.10 & \\
\hline \multirow{6}{*}{$\begin{array}{l}\text { CMJ Height } \\
\text { (m) }\end{array}$} & Mean & 0.327 & 0.341 & 0.360 & 0.313 & 0.324 & 0.328 \\
\hline & SD & 0.064 & 0.056 & 0.066 & 0.062 & 0.068 & 0.062 \\
\hline & $\% \mathrm{CV}$ & 4.05 & 3.12 & 2.78 & 3.29 & 3.92 & 2.36 \\
\hline & & \multicolumn{3}{|c|}{0.24} & \multicolumn{2}{|c|}{0.17} & \\
\hline & $d$ & \multirow{2}{*}{\multicolumn{3}{|c|}{$0.50^{*}{ }^{0.30}$}} & \multirow{2}{*}{\multicolumn{3}{|c|}{$0.23^{*}{ }^{0.05}$}} \\
\hline & & & & & & & \\
\hline \multirow{6}{*}{ CMJ TTT (s) } & Mean & 0.71 & 0.72 & 0.74 & 0.76 & 0.75 & 0.77 \\
\hline & SD & 0.09 & 0.10 & 0.09 & 0.09 & 0.09 & 0.10 \\
\hline & $\% \mathrm{CV}$ & 2.80 & 3.28 & 3.16 & 3.60 & 3.69 & 3.23 \\
\hline & & \multicolumn{3}{|c|}{0.07} & \multicolumn{2}{|c|}{0.08} & \\
\hline & $d$ & \multirow{2}{*}{\multicolumn{3}{|c|}{$0.29^{0.21}$}} & \multicolumn{3}{|c|}{0.19} \\
\hline & & & & & & 0.11 & \\
\hline \multirow{6}{*}{ RSImod } & Mean & 0.46 & 0.48 & 0.49 & 0.42 & 0.43 & 0.43 \\
\hline & SD & 0.09 & 0.09 & 0.09 & 0.09 & 0.09 & 0.09 \\
\hline & $\% \mathrm{CV}$ & 6.73 & 6.24 & 6.69 & 6.10 & 5.89 & 4.00 \\
\hline & & \multicolumn{3}{|c|}{0.20} & \multicolumn{3}{|c|}{0.20} \\
\hline & $d$ & \multicolumn{3}{|c|}{0.11} & \multicolumn{3}{|c|}{0.05} \\
\hline & & \multicolumn{3}{|c|}{0.29} & \multicolumn{3}{|c|}{0.16} \\
\hline
\end{tabular}

${ }^{*}=$ significant $(p<0.05)$ increase pre to post intervention

SJ: squat jump, CMJ: countermovement jump, TTT: time to take-off, RSImod: reactive strength index modified, SD: standard deviation, \%CV: percentage coefficient of variation, $d$ : Cohen's $d$ effect size

\section{ISOMETRIC MID-THIGH PULL}

Sphericity was assumed via Mauchley's test for all IMTP variables. The Catch and Pull groups both demonstrated significant $(p<0.001$; power $=0.931)$ increases in F100. Both groups showed trivial non-significant $(p>0.05)$ changes pre- to mid-intervention, with small significant 
385 (Catch: $17.3 \pm 22.0 \%, p=0.03$ Pull: $11.5 \pm 21.4 \%, p=0.04$ ) increases mid- to post-intervention 386 and pre- to post-intervention (Catch: $14.9 \pm 17.2 \%, p=0.011$ Pull: $15.5 \pm 16.0 \%, p=0.03$ ) 387 (Table 6). Trivial to small and non-significant differences $(d=0.08-0.23, p>0.05)$ in percentage 388 change F100 across phases (pre-mid: $-0.7 \pm 13.5 \%, 3.7 \pm 15.9 \%$, mid-post: $17.3 \pm 22.0 \%$, $38911.5 \pm 21.4 \%$, pre-post: $14.9 \pm 17.2 \%, 13.5 \pm 16.0 \%$ ), were evident between the Catch and 390 Pull groups, respectively (Figure 4a).

391 Both groups demonstrated significant $(p=0.005$; power $=0.855)$ increases in $\mathrm{F} 150$, with both 392 groups showing trivial to small non-significant $(p>0.05)$ changes pre- to mid-intervention, with 393 the Catch group demonstrating small significant $(16.5 \pm 20.4 \%, p=0.022)$ increases mid- to 394 post-intervention and the Pull group demonstrating small but non-significant $(12.0 \pm 22.9 \%, p$ $395>0.05)$ increases mid- to post-intervention. Both groups demonstrated moderate and 396 significant increases (Catch: $16.0 \pm 17.6 \%, p=0.003$ Pull: $16.2 \pm 18.4 \%, p=0.01$ ) in F150 397 pre- to post-intervention (Table 6). Trivial to small and non-significant differences $(d=0.01$ $3980.31, p>0.05$ ) in percentage change $F 150$ across phases (pre-mid: $0.9 \pm 14.9 \%, 5.9 \pm 17.5 \%$, 399 mid-post: $16.5 \pm 17.6 \%, 12.0 \pm 22.9 \%$, pre-post: $16.0 \pm 17.6 \%, 16.2 \pm 18.4 \%$ ), were evident 400 between the Catch and Pull groups, respectively (Figure $4 \mathrm{~b}$ ). 


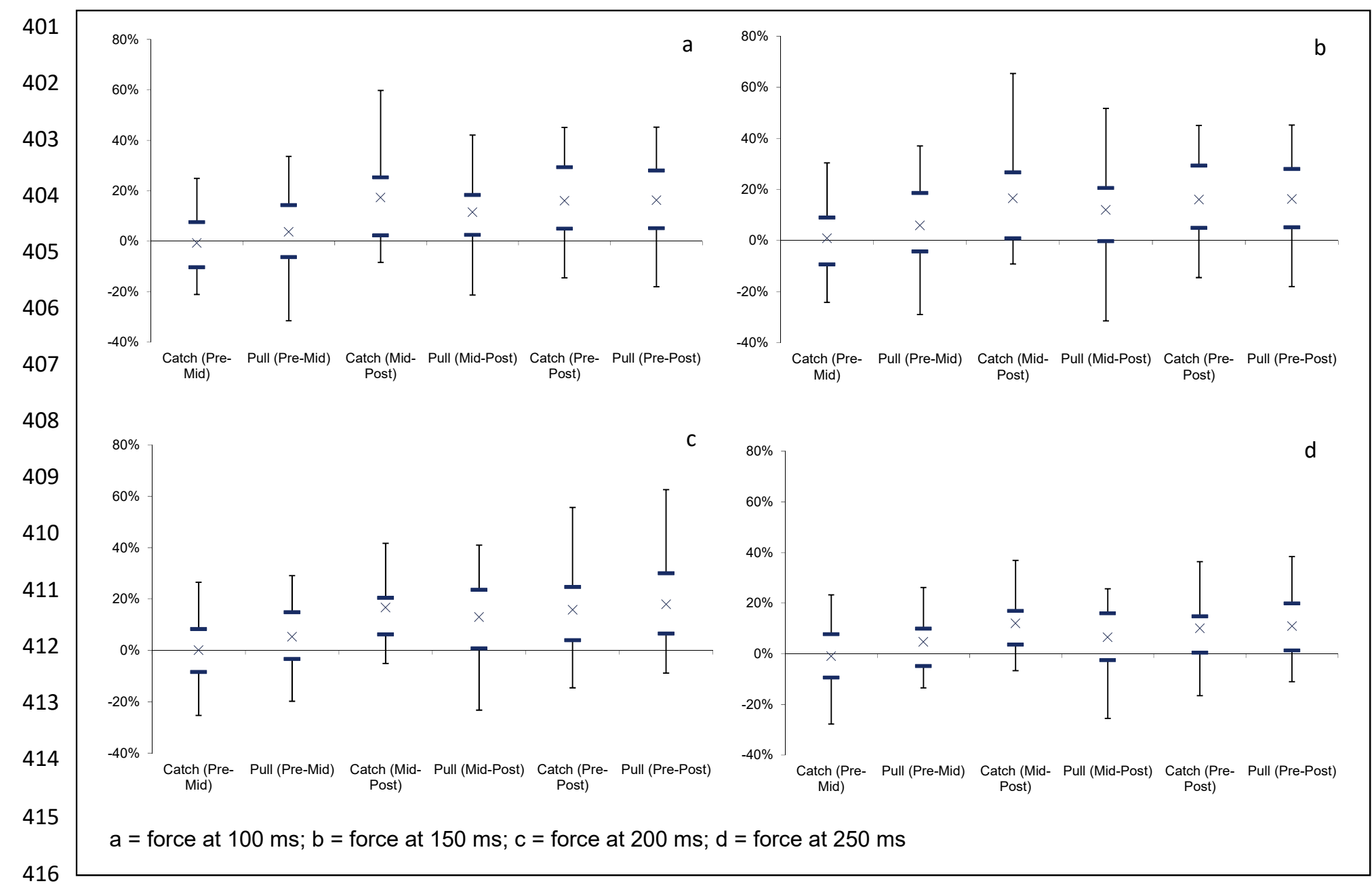

417 Figure 4: Comparison of percentage change in isometric mid-thigh pull time specific force variables, across time points, for the 418 Catch and Pull groups 
419 Both groups demonstrated significant $(p=0.007$; power $=0.842)$ increases in F200. Both

Both groups demonstrated significant $(p=0.007$; power $=0.834)$ increases in $\mathrm{F} 250$, with the Catch group showing a trivial non-significant $(p>0.05)$ decrease pre- to mid-intervention, while the Pull group showed a small but non-significant increase $(p>0.05)$. The Catch croup demonstrated a small significant $(12.0 \pm 16.6 \%, p=0.045)$ increase mid- to post-intervention and small significant increase pre- to post-intervention $(10.0 \pm 16.1 \%, p=0.025)$, while the Pull group demonstrated a small significant $(6.5 \pm 13.4 \%, p=0.045)$ increase mid- to postintervention and small significant increase pre- to post-intervention $(10.9 \pm 14.4 \%, p=0.025)$ (Table 6). Trivial to small and non-significant differences $(d=0.06-0.47, p>0.05)$ in percentage change F250 were evident, across phases (pre-mid: $-1.0 \pm 12.5 \%, 4.7 \pm 11.7 \%$, mid-post: 12.0 $\pm 16.6 \%, 6.5 \pm 13.4 \%$, pre-post: $10.0 \pm 16.1 \%, 10.9 \pm 14.4 \%$ ), between the Catch and Pull groups, respectively (Figure $4 d$ ).

Both groups demonstrated significant $(p=0.001$; power $=0.869)$ and progressive increases in relative PF, with the Catch group showing a trivial non-significant $(p>0.05)$ increase pre- to mid-intervention, while the Pull group showed a small but significant increase $(p=0.017)$. In contrast the Catch group demonstrated a small significant $(8.4 \pm 10.8 \%, p=0.028)$ increase mid- to post-intervention while the Pull group demonstrated a trivial non-significant $(p>0.05)$ increase in relative PF. Both groups demonstrated small significant increases (Catch: $13.7 \pm$ $18.7 \%, p=0.021$; Pull: $9.7 \pm 16.3 \%, p=0.045$ ) in relative PF pre- to post-intervention (Table $6)$. The Catch group demonstrated a moderately and significantly greater $(d=0.84, p=0.014)$ increase in PF mid- to post-intervention ( $8.4 \pm 10.8 \%$ ) compared to the Pull group $(0.2 \pm 8.5 \%)$. There were, however, only small and non-significant differences $(d=0.23-0.45, p>0.05)$ in percentage change PF pre- to mid-intervention ( $4.6 \pm 9.6 \%, 9.8 \pm 13.1 \%$ ) or pre- to postintervention (13.7 $\pm 18.7 \%, 9.7 \pm 16.3 \%)$, between the Catch and Pull groups, respectively (Figure 5a). 
Table 6: Changes in isometric mid-thigh pull performance

\begin{tabular}{|c|c|c|c|c|c|c|c|}
\hline & \multirow[t]{2}{*}{ Group } & \multicolumn{3}{|c|}{ Catch } & \multicolumn{3}{|c|}{ Pull } \\
\hline & & Pre & Mid & Post & Pre & Mid & Post \\
\hline \multirow{6}{*}{ F100 ms (N.kg-1) } & Mean & 20.00 & 19.95 & 22.92 & 17.93 & 18.49 & 20.14 \\
\hline & SD & 5.07 & 4.52 & 5.94 & 3.74 & 4.06 & 4.11 \\
\hline & $\% \mathrm{CV}$ & 5.48 & 8.68 & 7.76 & 6.68 & 9.30 & 8.20 \\
\hline & & \multicolumn{3}{|c|}{0.01} & \multicolumn{2}{|c|}{0.14} & \\
\hline & $d$ & \multicolumn{3}{|c|}{$0.46^{*}$} & \multicolumn{3}{|c|}{$0.40^{*}$} \\
\hline & & \multicolumn{3}{|c|}{$0.45^{*}$} & \multicolumn{3}{|c|}{$0.56^{*}$} \\
\hline \multirow{6}{*}{ F150 ms (N.kg-1) } & Mean & 24.76 & 25.11 & 28.67 & 22.07 & 23.28 & 25.21 \\
\hline & SD & 6.23 & 5.49 & 6.61 & 5.44 & 6.22 & 5.37 \\
\hline & $\% \mathrm{CV}$ & 5.66 & 8.79 & 5.83 & 9.26 & 10.84 & 8.75 \\
\hline & & \multicolumn{3}{|c|}{0.06} & \multicolumn{2}{|c|}{0.21} & \\
\hline & $d$ & \multicolumn{3}{|c|}{$0.59^{*}$} & \multicolumn{3}{|c|}{0.33} \\
\hline & & \multicolumn{3}{|c|}{$0.61^{*}$} & \multicolumn{3}{|c|}{$0.58^{*}$} \\
\hline \multirow{6}{*}{ F200 ms (N.kg-1) } & Mean & 28.20 & 28.22 & 31.36 & 25.42 & 26.74 & 28.54 \\
\hline & SD & 6.22 & 5.41 & 6.68 & 5.51 & 6.47 & 5.95 \\
\hline & $\% \mathrm{CV}$ & 4.75 & 7.76 & 4.04 & 7.56 & 9.52 & 8.95 \\
\hline & & \multicolumn{3}{|c|}{0.03} & \multicolumn{2}{|c|}{0.23} & \\
\hline & $d$ & \multicolumn{3}{|c|}{$0.52^{*}$} & \multicolumn{3}{|c|}{0.29} \\
\hline & & \multicolumn{3}{|c|}{$0.49^{*}$} & \multicolumn{3}{|c|}{$0.54^{*}$} \\
\hline \multirow{6}{*}{ F250 ms (N. kg $\left.{ }^{-1}\right)$} & Mean & 29.72 & 29.27 & 32.47 & 26.90 & 28.16 & 29.67 \\
\hline & SD & 6.30 & 5.31 & 6.31 & 5.45 & 6.36 & 6.53 \\
\hline & $\% \mathrm{CV}$ & 4.18 & 6.99 & 2.89 & 5.75 & 7.32 & 8.54 \\
\hline & & \multicolumn{3}{|c|}{0.00} & \multicolumn{2}{|c|}{0.21} & \\
\hline & $d$ & \multicolumn{3}{|c|}{$0.47^{*}$} & \multicolumn{3}{|c|}{0.23} \\
\hline & & & $0.44^{*}$ & & & $0.46^{*}$ & \\
\hline & Mean & 36.83 & 38.18 & 41.20 & 34.69 & 37.94 & 37.98 \\
\hline & SD & 8.00 & 7.02 & 7.51 & 5.66 & 6.67 & 7.95 \\
\hline Peak Force $\left(\mathrm{N} \mathrm{kg}^{-1}\right)$ & $\% \mathrm{CV}$ & 3.72 & 3.21 & 3.74 & 3.58 & 2.99 & 3.06 \\
\hline & & & & & & & \\
\hline & $d$ & & & & & & \\
\hline & & & $0.56^{*}$ & & & $0.48^{*}$ & \\
\hline
\end{tabular}

461

For the relative $\mathrm{PC}$, sphericity was assumed via Mauchley's test, with both groups demonstrating significant $(p<0.001$; power $=1.00)$ increases in relative PC 1RM. The Catch group showed small significant $(d=0.44, p=0.01)$ increases pre- $\left(0.93 \pm 0.15 \mathrm{~kg} \cdot \mathrm{kg}^{-1}\right)$ to midintervention $\left(0.99 \pm 0.12 \mathrm{~kg}_{\mathrm{kg}}{ }^{-1}\right)$, with trivial non-significant $(d=0.15, p=0.14)$ increases midto post-intervention $\left(1.01 \pm 0.14 \mathrm{~kg} \cdot \mathrm{kg}^{-1}\right)$, resulting in a small significant $(d=0.55, p<0.001)$ 
470 with trivial, yet significant $(d=0.17, p=0.015)$ increases mid- to post-intervention $(0.98 \pm 0.18$ $\left.471 \mathrm{~kg} \cdot \mathrm{kg}^{-1}\right)$, resulting in a small significant $(d=0.39, p<0.001)$ increase pre- to post-intervention. 472 There were small non-significant differences $(p>0.05)$ in percentage change in relative PC 473 performance pre- to mid-intervention $(7.4 \pm 5.0 \%, 5.4 \pm 5.4 \%, d=0.38)$ mid- to post474 intervention $(1.9 \pm 0.8 \%, 2.9 \pm 4.1 \%, d=0.34)$ and only trivial differences pre- to post 475 intervention $(9.5 \pm 6.2 \%, 8.4 \pm 6.1 \%, d=0.18)$ between the Catch and Pull groups, respectively 476 (Figure 5b).

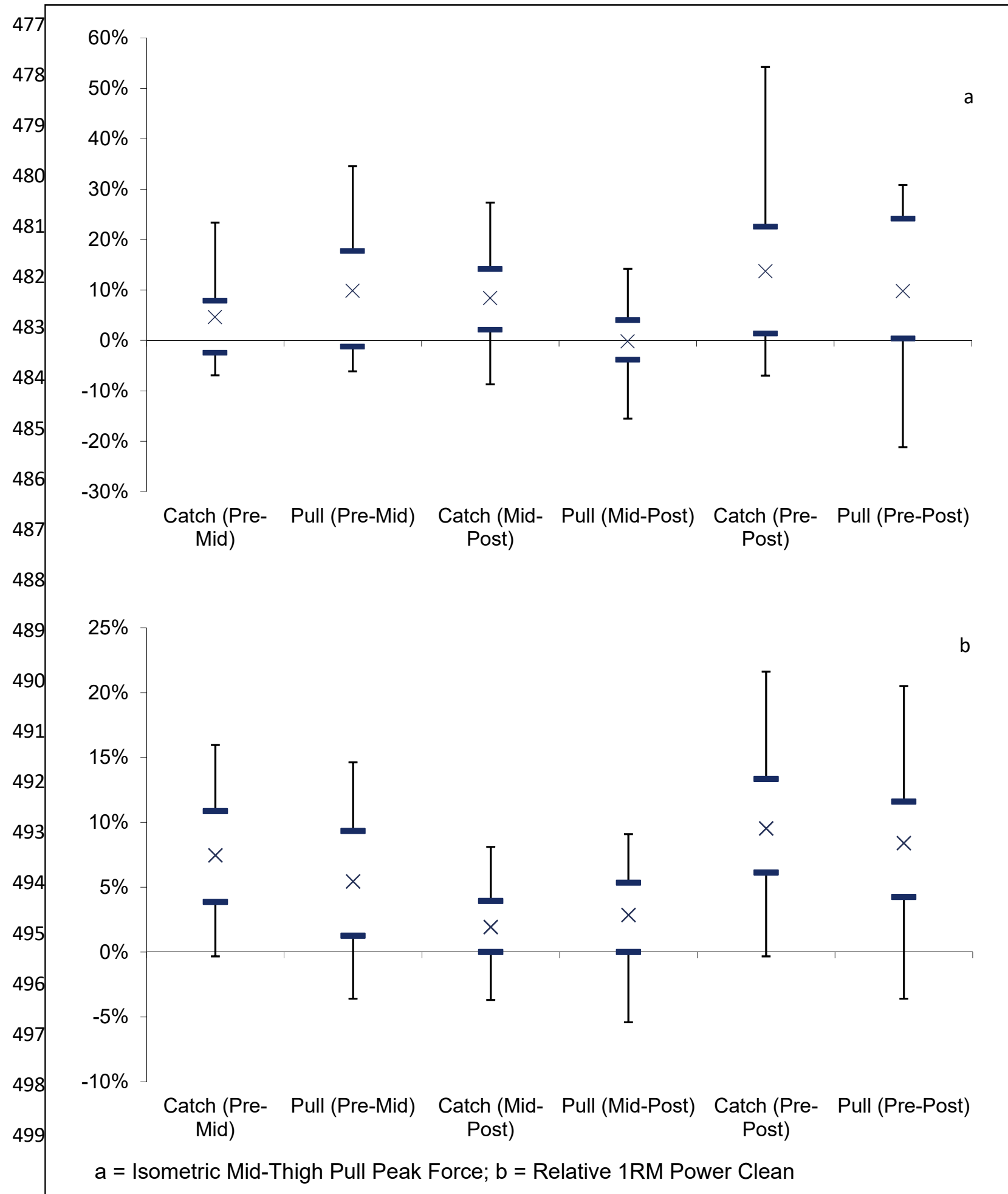


500 Figure 5: Comparison of percentage change in isometric mid-thigh pull peak force and 501 relative one repetition maximum power clean performances, across time points, for the 502 Catch and Pull groups

There were no significant $(p>0.05)$ changes in body mass for either the Catch (Pre $71.14 \pm$ $50511.79 \mathrm{~kg}$; Mid $71.03 \pm 11.48 \mathrm{~kg}$; Post $70.95 \pm 11.07 \mathrm{~kg}$ ) or the Pull group (Pre $66.43 \pm 10.13$ $\mathrm{kg}$; Mid $66.64 \pm 9.97 \mathrm{~kg}$; Post $66.68 \pm 10.11 \mathrm{~kg}$ ) across the duration of the intervention.

\section{Discussion}

This is the first study to compare the effects of including or excluding the catch phase of PC derivatives, on training adaptations, in terms of force-time characteristics during dynamic and isometric tasks. Both groups demonstrated improvements in CMJ height, IMTP variables and PC performance pre- to post-intervention, as hypothesized. In contrast to the hypotheses, the Catch group increased SJ height, whereas there was no change in the Pull group. Also in contrast to the hypotheses, there was no difference in percentage change, in any variables, between groups, which may be attributed to the comparable training stimulus during the propulsion phase of each exercise along with the identical volume load.

The Catch group achieved moderate improvements in SJ height (12.6\%) across the duration of the intervention, whereas the Pull group only demonstrated trivial increases $(2.1 \%)$. It is possible that this difference is due to the requirement to rapidly produce force to arrest motion during the Catch, whereas a greater time is available to decelerate the barbell and the system center of mass during the pulling derivatives. The Catch group also exhibited greater improvements in CMJ height $(10.8 \%)$, compared to the Pull group $(5.2 \%)$ across the duration of the study, although improvements in both groups were small and significant, the difference in improvements between groups was small yet not significant. To achieve the CMJ heights, there were no meaningful or significant changes in TTT, implying that an increase in jump height must have been a result of an increase in force applied, resulting in an increased impulse and therefore velocity at take-off. The lack of change in TTT, combined with the increase in jump height, resulted in favorable, yet small and non-significant increases in RSImod for both the Catch (7.0\%) and Pull (4.4\%) groups (Figure 3). The small magnitudes of increases in jump performance are in line with previous findings, reported after a 10-week training intervention comparing the training effects of hang high pulls and hexagonal barbell jump squats, in collegiate swimmers (37). In addition, the transfer of weightlifting style training, has recently been reported to result in only small changes in jump performance over relatively short training periods (26), as observed here. In contrast however, traditional resistance training combined with weightlifting derivatives has been shown to enhance longitudinal maximal strength and jump performance (30).

538 Both groups demonstrated trivial to small and non-significant increases in time-specific force 539 values during the initial four weeks (pre- to mid- intervention), with small to moderate and 540 significant increases in the final four weeks (mid- to post-intervention). This resulted in small 541 to moderate increases in F100 (14.9\%; 15.5\%), F150 (16.0\%; 16.2\%), F200 (15.8\%: 17.9\%) 542 and F250 (15.8\%; 17.9\%) for the Catch and Pull groups respectively. The greater increases 
543 in time-specific force production, during the second four weeks of training, may be due the 544 higher intensities used, resulting in the subjects having to ensure a maximal intent and rapid 545 force production to adequately accelerate the barbell. The Pull group consistently 546 demonstrated a greater percentage change in all time-specific forces although these 547 differences were small and non-significant (Figure 4). These observations are similar to those 548 previously reported by Oranchuk et al. (37) who also reported no meaningful differences in 549 relative $\mathrm{PF}$ and time-specific force variables, after 10-weeks of hang high pull versus 550 hexagonal barbell jump squat training.

551 In contrast to the changes in IMTP time-specific forces, PF increased to the greatest extent 552 during the first four weeks (pre-mid), with the Catch group demonstrating greater 553 improvements (13.7\%) compared to the Pull group (9.7\%), although the differences between 554 groups were trivial. Interestingly, PC performances exhibited similar trends, with the greatest 555 improvements occurring during the first 4 weeks, and the Catch group demonstrating slightly 556 greater improvements $(9.5 \%)$ compared to the Pull group (8.4\%). It is likely that similarity in 557 these adaptations are due to the strong relationships between IMTP PF and PC performance 558 previously reported (33). These greater increases in PC performance, during the first four 559 weeks, may be due to the slightly greater volume of power clean derivatives performed during 560 this phase, compared to the second phase. The magnitude of the changes in PC performance 561 is also greater than the smallest worthwhile change previously reported to indicate meaningful 562 changes for the PC $(9,14)$ and the $\operatorname{IMTP}(7,14)$.

563 Both the groups improved their 1RM PC over the course of the training interventions. 564 Interestingly, the Pull group were able to improve their 1RM PC to a similar extent compared 565 to the Catch group despite not training with the catch phase. This is important to note 566 considering not all individuals are able to adequately perform the catch phase due to poor 567 technique, inflexibility or previous or current injury. Thus, training with pulling derivatives may 568 provide an effective training stimulus for improving maximal dynamic strength, which is 569 comparable to the use of weightlifting catching derivatives. As mentioned above, each training 570 group exhibited small, significant training effects over the course of the study, with only a trivial 571 difference, in the percentage increase in performance, between groups. From a specificity 572 standpoint, this finding is unsurprising given that this group performed submaximal training 573 with the PC exercise. These improvements in PC $(9,14,17)$ and IMTP $(7,14)$ performance 574 were also greater than the between session smallest detectable differences previously 575 reported.

576 A potential limitation to the current study was the use of identical loading procedures between 577 the Catch and Pull groups. In an effort to equalize training volume, each group was prescribed 578 the same relative intensity and volume load, during each training block. While this may make 579 sense from a research standpoint, the pulling derivatives implemented within the current study 580 (e.g. clean grip mid-thigh pull and pull from the floor) are typically implemented using loads in 581 excess of an athlete's 1RM PC (i.e. > 100\%) $(8,10,22,31)$, while additional repetitions may 582 be able to be performed at submaximal loads, compared to catch variations. Thus, the loads 583 implemented for these exercises may not have provided an adequate load or volume stimulus 584 to the Pull group, which may have prevented them from displaying greater training benefits 585 compared to the Catch group. Given that weightlifting pulling derivatives may produce greater 586 force and velocity characteristics, dependent on the load used (43), researchers may consider 587 investigating the training effects of weightlifting pulling derivatives that use loads which 
emphasize either a force or velocity overload stimulus, as described by Suchomel et al., (43), compared to training with weightlifting catching derivatives.

It is also worth noting, that as this was an in-season training intervention, with relatively low training volumes, to minimize any potentially negative impact on the athletes' competitive performances, a future study conducted in pre-season, is recommended, where higher training volume loads and, or relative intensities (based on 1RM PC performance) can be incorporated.

\section{Practical Application}

The results of this study indicate that training with either weightlifting catching or weightlifting pulling derivatives improved the athletes' performance across a spectrum of variables. It is important to note, however that trivial to small differences existed between training groups when examining every variable, indicating that catching and pulling derivatives may provide a similar training stimulus when the same relative intensity (based on 1RM PC) and volume loads are implemented during an in-season training program. Thus, both catching and pulling derivatives may provide an effective training stimulus when training to improve strength-power characteristics. It is suggested, therefore, that strength and conditioning coaches and athletes should appropriately periodize the use of weightlifting derivatives, and that pulling and catching derivatives can be used interchangeable to achieve similar goals, when performed using the same relative intensity and volume loads.

Acknowledgements: The authors would like to acknowledge Matthew Cuthbert, Rachel Higgins and Daniel Traynor for their assistance during the coaching sessions. We would also like to thank the participants for their time and efforts, and the NSCA for supporting this investigation as part of the International Collaboration Grant.

Funding: This study was funded by the NSCA foundation, as part of the International Collaboration Grant scheme (awarded 2016).

The authors report no conflict of interest and the finding of the study do not represent the views of the NSCA. 


\section{References}

1. Baechle TR, Earle RW, and Wathen D. Resistance Training, in: Essentials of Strength Training and Conditioning. TR Baechle, Earle, R. W, ed. Champaign, Illinois: Human Kinetics, 2008, pp 381-412.

2. Beckham G, Mizuguchi S, Carter C, Sato K, Ramsey M, Lamont H, Hornsby G, Haff G, and Stone M. Relationships of isometric mid-thigh pull variables to weightlifting performance. $J$ Sports Med Phys Fitness 53: 573-581, 2013.

3. Beckham GK, Sato K, Mizuguchi S, Haff GG, and Stone MH. Effect of Body Position on Force Production During the Isometric Mid-Thigh Pull. J Strength Cond Res. Publish Ahead of Print, 2017.

4. Canavan PK, Garrett GE, and Armstrong LE. Kinematic and Kinetic Relationships Between an Olympic-Style Lift and the Vertical Jump. J Strength Cond Res. 10: 127-130, 1996.

5. Comfort $P$, Allen $M$, and Graham-Smith P. Comparisons of peak ground reaction force and rate of force development during variations of the power clean. J Strength Cond Res 25: 1235-1239, 2011.

6. Comfort P, Graham-Smith P, and Allen M. Kinetic comparisons during variations of the Power Clean. J Strength Cond Res 25: 3269-3273, 2011.

7. Comfort P, Jones PA, McMahon JJ, and Newton R. Effect of knee and trunk angle on kinetic variables during the isometric midthigh pull: test-retest reliability. Int I Sports Physiol Perform 10: 58-63, 2015.

8. Comfort P, Jones PA, and Udall R. The effect of load and sex on kinematic and kinetic variables during the mid-thigh clean pull. Sports Biomech 14: 139-156, 2015.

9. Comfort $\mathrm{P}$ and McMahon JJ. Reliability of Maximal Back Squat and Power Clean Performances in Inexperienced Athletes. J Strength Cond Res. 29: 3089-3096, 2015.

10. Comfort $P$, Udall $R$, and Jones $P$. The affect of loading on kinematic and kinetic variables during the mid-thigh clean pull. J Strength Cond Res 26: 1208-1214, 2012.

11. Comfort P, Williams R, Suchomel TJ, and Lake JP. A comparison of catch phase force-time characteristics during clean derivatives from the knee. J Strength Cond Res. 21 (7): 2017.

12. Cormack SJ, Newton RU, McGuigan MR, and Doyle TL. Reliability of measures obtained during single and repeated countermovement jumps. Int I Sports Physiol Perform 3: 131-144, 2008.

13. Dos'Santos T, Jones PA, Comfort P, and Thomas C. Effect of Different Onset Thresholds on Isometric Mid-Thigh Pull Force-Time Variables. J Strength Cond Res Publish Ahead of Print, 2017.

14. Dos'Santos T, Thomas C, Comfort P, McMahon JJ, Jones PA, Oakley NP, and Young AL. Between-Session Reliability Of Isometric Mid-Thigh Pull Kinetics And Maximal Power Clean Performance In Male Youth Soccer Players. J Strength Cond Res Published ahead of print, 2017.

15. Dos'Santos T, Thomas C, Jones PA, McMahon JJ, and Comfort P. The Effect Of Hip Joint Angle On Isometric Mid-Thigh Pull Kinetics. J Strength Cond Res. Publish Ahead of Print, 2017.

16. Enoka RM. The pull in olympic weightlifting. Med Sci Sports 11: 131-137, 1979.

17. Faigenbaum AD, McFarland JE, Herman RE, Naclerio F, Ratamess NA, Kang J, and Myer GD. Reliability of the one-repetition-maximum power clean test in adolescent athletes. $J$ Strength Cond Res 26: 432-437, 2012.

18. Garhammer J and Gregor R. Propulsion Forces as a Function of Intensity for Weightlifting and Vertical Jumping. J Strength Cond Res. 6: 129-134, 1992.

19. Haff GG, Carlock JM, Hartman MJ, Kilgore JL, Kawamori N, Jackson JR, Morris RT, Sands WA, and Stone $\mathrm{MH}$. Force-time curve characteristics of dynamic and isometric muscle actions of elite women olympic weightlifters. J Strength Cond Res 19: 741-748, 2005. 
674 20. Haff GG, Ruben RP, Lider J, Twine C, and Cormie P. A Comparison of Methods for Determining the Rate of Force Development During Isometric Mid-Thigh Clean Pulls. J Strength Cond Res 29: 386-395, 2015.

21. Haff GG, Stone M, O'Bryant HS, Harman E, Dinan C, Johnson R, and Han K-H. Force-Time Dependent Characteristics of Dynamic and Isometric Muscle Actions. J Strength Cond Res 11: 269-272, 1997.

22. Haff GG, Whitley A, McCoy LB, O'Bryant HS, Kilgore JL, Haff EE, Pierce K, and Stone MH. Effects of Different Set Configurations on Barbell Velocity and Displacement During a Clean Pull. J Strength Cond Res 17: 95-103, 2003.

23. Halperin I, Williams KJ, Martin DT, and Chapman DW. The Effects of Attentional Focusing Instructions on Force Production During the Isometric Midthigh Pull. J Strength Cond Res 30: 919-923, 2016.

24. Halperin I, Williams KJ, Martin DT, and Chapman DW. The Effects of Attentional Focusing Instructions on Force Production During the Isometric Midthigh Pull. J Strength Cond Res. 30: 919-923, 2016.

25. Harbili E and Alptekin A. Comparative kinematic analysis of the snatch lifts in elite male adolescent weightlifters. J Sports Sci Med 13: 417-422, 2014.

26. Helland C, Hole E, Iversen E, Olsson MC, Seynnes O, Solberg PA, and Paulsen G. Training Strategies to Improve Muscle Power: Is Olympic-style Weightlifting Relevant? Med Sci Sports Exerc 49: 736-745, 2017.

27. http://sportsci.org/resource/stats/index.html. Accessed 08/05/15/2015.

28. Hopkins WG, Marshall SW, Batterham AM, and Hanin J. Progressive statistics for studies in sports medicine and exercise science. Med Sci Sports Exerc 41: 3-13, 2009.

29. Hori N, Newton RU, Andrews WA, Kawamori N, McGuigan MR, and Nosaka K. Does Performance of Hang Power Clean Differentiate Performance of Jumping, Sprinting, and Changing of Direction? J Strength Cond Res 22: 412-418 2008.

30. Kavanaugh AA, Mizuguchi S, Sands WA, Ramsey MW, and Stone MH. Long-Term Changes In Jump Performance And Maximum Strength In A Cohort Of Ncaa Division I Women's Volleyball Athletes. J Strength Cond Res Publish Ahead of Print, 2017.

31. Kawamori N, Rossi SJ, Justice BD, Haff EE, Pistilli EE, O'Bryant HS, Stone MH, and Haff GG. Peak Force and Rate of Force Development During Isometric and Dynamic Mid-Thigh Clean Pulls Performed At Various Intensities. J Strength Cond Res 20: 483-491, 2006.

32. Kipp K, Malloy PJ, Smith J, Giordanelli MD, Kiely MT, Geiser CF, and Suchomel TJ. Mechanical Demands of the Hang Power Clean and Jump Shrug: A Joint-level Perspective. J Strength Cond Res Publish Ahead of Print, 2017.

33. McGuigan $\mathrm{M}$ and Winchester JB. The relationship between isometric and dynamic strength in collegiate football players. J Sports Sci Med 7: 101-105, 2008.

34. McMahon JJ, Jones PA, Suchomel TJ, Lake J, and Comfort P. Influence of Reactive Strength Index Modified on Force- and Power-Time Curves. Int J Sports Physiol Perform E-pub ahead of print: 1-24, 2017.

35. Moir GL. Three Different Methods of Calculating Vertical Jump Height from Force Platform Data in Men and Women. Measurement in Physical Education and Exercise Science 12: 207218, 2014.

36. Moolyk AN, Carey JP, and Chiu LZF. Characteristics of Lower Extremity Work During the Impact Phase of Jumping and Weightlifting. J Strength Cond Res 27: 3225-3232, 2013.

37. Oranchuk DJ, Robinson TL, Switaj ZJ, and Drinkwater EJ. Comparison of the Hang High-Pull and Loaded Jump Squat for the Development of Vertical Jump and Isometric Force-Time Characteristics. J Strength Cond Res, 2017.

38. Owen NJ, Watkins J, Kilduff LP, Bevan HR, and Bennett MA. Development of a criterion method to determine peak mechanical power output in a countermovement jump. $J$ Strength Cond Res 28: 1552-1558, 2014. 
39. Souza AL, Shimada SD, and Koontz A. Ground reaction forces during the power clean. J Strength Cond Res 16: 423-427, 2002.

40. Stone MH, Sanborn KIM, O'Bryant HS, Hartman M, Stone ME, Proulx C, Ward B, and Hruby JOE. Maximum Strength-Power-Performance Relationships in Collegiate Throwers. J Strength Cond Res 17: 739-745, 2003.

41. Suchomel T, Comfort $P$, and Stone M. Weightlifting Pulling Derivatives: Rationale for Implementation and Application. Sports Medicine 45: 823-839, 2015.

42. Suchomel TJ, Bailey CA, Sole CJ, Grazer JL, and Beckham GK. Using reactive strength indexmodified as an explosive performance measurement tool in Division I athletes. J Strength Cond Res 29: 899-904, 2015.

43. Suchomel TJ, Comfort P, and Lake JP. Enhancing the Force-Velocity Profile of Athletes Using Weightlifting Derivatives. Strength \& Conditioning Journal 39: 10-20, 2017.

44. Suchomel TJ, Lake JP, and Comfort P. Load absorption force-time characteristics following the second pull of weightlifting derivatives. J Strength Cond Res 31: 1644-1652, 2017.

45. Suchomel TJ and Sole CJ. Force-Time Curve Comparison Between Weightlifting Derivatives. International Journal of Sports Physiology and Performance Published ahead of print, 2017.

46. Suchomel TJ and Sole CJ. Power-Time Curve Comparison between Weightlifting Derivatives. J Sports Sci Med 16: 407-413, 2017.

47. Suchomel TJ, Wright GA, Kernozek TW, and Kline DE. Kinetic Comparison of the Power Development Between Power Clean Variations. J Strength Cond Res 28: 350-360, 2014.

\section{Figure and Table Legends:}

Figure 1: Summary of testing schedule

Figure 2: Testing sequence (SJ: squat jump, CMJ: countermovement jump, IMTP: Isometric Mid-Thigh Pull) 
776 Figure 3: Comparison of percentage change in jump variables across time points for the Catch

777 and Pull groups

778 Figure 4: Comparison of percentage change in isometric mid-thigh pull time specific force 779 variables, across time points, for the Catch and Pull groups

780 Figure 5: Comparison of percentage change in isometric mid-thigh pull peak force and relative 781 one repetition maximum power clean across time points for the Catch and Pull groups

783

784

Table 1: Training sessions, weeks 1-4

785 Table 2: Training sessions, weeks 6-9

786 Table 3: Within and between session reliability (ICC (95\% confidence intervals)) and variability 787 (\% coefficient of variation) of jump performance variables

788 Table 4: Within and between session reliability (ICC (95\% confidence intervals)) and variability 789 (\% coefficient of variation) of IMTP variables

790 Table 5: Changes in jump performance

791 Table 6: Changes in isometric mid-thigh pull performance 